\title{
Cost-consequence analysis of sitagliptin versus sulfonylureas as add-on therapy for the treatment of diabetic patients in Italy
}

This article was published in the following Dove Press journal:

ClinicoEconomics and Outcomes Research

Number of times this article has been viewed

\section{Valentina Lorenzoni' \\ Fabio Baccetti ${ }^{2}$ \\ Stefano Genovese ${ }^{3}$ \\ Enrico Torre ${ }^{4}$ \\ Giuseppe Turchetti'}

'Institute of Management, Scuola Superiore Sant'Anna, Pisa, Italy; ${ }^{2} \mathrm{SD}$ Diabetology, ASL Toscana Nordovest, Massa Carrara, Italy; ${ }^{3}$ Cardiovascular and Metabolic Department, IRCCS Multimedica Sesto San Giovanni, Milan, Italy; ${ }^{4}$ SSD Endocrinologia, Diabetologia e Malattie metaboliche, ASL 3 Genovese, Genoa, Italy

Correspondence: Giuseppe Turchetti Istituto di Management, Scuola Superiore Sant'Anna, Piazza Martiri della Libertà $n$. 33, 56127 Pisa, Italy

Tel +39050883808

Email g.turchetti@sssup.it
Objective: Diabetes mellitus is a chronic disease related to a significant impact in both epidemiologic and economic terms. In Italy, around 3.6 million people are affected by diabetes and this number is expected to increase significantly in the next few years. As recommended by current national and international guidelines, metformin (Met) is prescribed as first-line pharmacological treatment, and many pharmacological alternatives are available for patients uncontrolled with Met monotherapy. Despite the availability of many innovative oral antidiabetic drugs (OADs), such as dipeptidyl peptidase 4 inhibitors (DPP4-i) and its first-in-class sitagliptin (SITA), which entered the Italian market in the last 10 years, their usage is consistently lower than traditional drugs such as sulfonylureas (SUs). In fact, due to higher acquisition costs, the prescription of innovative OADs in Italy is restricted to specialist, resulting in a prominent usage of traditional $\mathrm{OAD}$ that can be prescribed also by general practitioners (GPs). A cost consequence analysis (CCA) was performed in order to compare SITA with SU, as second-line therapy in add-on to Met, in terms of costs and related clinical events over 36 months.

Methods: A CCA was conducted on a hypothetical cohort of 100,000 type 2 diabetes mellitus (T2DM) patients uncontrolled with Met monotherapy, from both the Italian National Health Service (INHS) and societal perspective. Therefore, both direct (drugs, self-monitoring, hypoglycemia, major cardiovascular events [MACEs], and switch to insulin) and indirect costs (expressed in terms of productivity losses) were evaluated. Clinical and economic data were collected through Italian national tariffs, literature, and experts' opinions. Three expert clinicians finally validated data inputs. To assess robustness of base case results, a one-way sensitivity analysis (OWSA) and a conservative scenario analysis - excluding MACEs - were carried out. Results: In the base case analysis, the higher drug costs related to SITA were offset by other management costs (ie, lower use of devices for glycemia self-monitoring, lower incidence of hypoglycemia and MACE, and delay to insulin switch). As a result, the economic evaluation showed that, compared to SU, SITA was cost saving from both societal $(-€ 61,217,723)$ and INHS (-€51,846,442) perspectives over 3 years as add-on to Met. The base case results were also confirmed by the scenario analysis and by the OWSA performed on the key parameters. The adoption of SITA, in a cohort of 100,000 diabetes patients, would avoid 26,882 non-severe hypoglycemic events, 6,528 severe hypoglycemic events, and 1,562 MACEs.

Conclusion: This analysis suggests that, compared to SU, SITA could be a sustainable and costsaving alternative for the management of T2DM patients uncontrolled with Met monotherapy from both clinical and economic perspectives.

Keywords: diabetes, dipeptidyl peptidase 4 inhibitors, sitagliptin, sulfonylurea, costconsequence analysis 


\section{Introduction}

Type 2 diabetes mellitus (T2DM) is a chronic degenerative disease associated with a high risk of chronic complications and comorbidities. It is one of the main public health challenges of the 21st century and it is responsible for a significant epidemiologic and economic burden.

According to the International Diabetes Federation (IDF), in 2015, about 415 million adults were diabetic (about 1 out of 11) and 5 million deaths were attributed to diabetes. ${ }^{1}$ As reported by the WHO, without primary prevention, the diabetes epidemic and its economic burden are going to increase, and it has been estimated to become one of the world's main killers across the next 20 years.

From the economic point of view, diabetes epidemic accounted for US $\$ 673$ billion in 2015 , with a significant impact on both direct and indirect costs that is expected to increase in the next few years in view of the growing prevalence, its complications, and changing health care pathways and technology. ${ }^{1}$

In Italy, prevalence of diabetes is about 5.5\% (mainly type 2 diabetes). ${ }^{2}$ As reported in the ARNO study, in Italy, the mean annual direct costs were estimated to be $€ 2,792$ per diabetic patient in 2012 (51\% due to hospitalization, 32\% due to drugs, and $17 \%$ due to specialist visits). ${ }^{3}$ However, the analysis did not take into account self-monitoring of blood glucose (SMBG) costs that represent a significant cost component in the management of diabetes. ${ }^{4} \mathrm{~A}$ recent cost of illness (COI) analysis, carried out on a cohort of 2.6 million diabetic treated patients in Italy, also showed that the overall economic burden related to diabetes was $€ 20.3$ billion/year (95\% CI: $€ 18.61$ to $€ 22.29$ billion), $54 \%$ of which was due to productivity loss ( $95 \% \mathrm{CI}: € 10.10$ to $€ 11.62$ billion) and $46 \%$ due to direct costs ( $95 \% \mathrm{CI}: € 8.11$ to $€ 11.06$ billion). This means that economic burden of diabetes increases dramatically when considering also indirect costs because of productivity loss borne by society. ${ }^{5}$

In Italy, as recommended by current national and international guidelines, metformin (Met) is prescribed as first-line pharmacological treatment. ${ }^{6}$

For patients not achieving glycemic targets with Met monotherapy, a wide range of oral antidiabetic drugs (OADs) is currently used as add-on therapy. In particular, in the past few years, new oral hypoglycemic drugs have been introduced into the market and, among these, dipeptidyl peptidase 4 inhibitors (DPP4-i) represent a valid alternative both in terms of efficacy - as compared to traditional OADs - and safety because of reduced adverse events (eg, hypoglycemic episodes and cardiovascular complications). ${ }^{7-9}$
Among all innovative molecules that entered the Italian market in the last 10 years, the market leader is nowadays represented by sitagliptin (SITA), the first in class DPP4-i. However, despite the availability of innovative classes of OADs, SU still represents the class of drugs mostly used in second line as add-on to Met. ${ }^{10}$

That happens because, in view of their higher acquisition costs, the prescription of innovative OADs is currently restricted to specialists, as opposed to traditional drugs, such as SU, which can also be prescribed by general practitioners (GPs).

On this basis, a cost consequence analysis (CCA), aimed at assessing the economic impact of SITA, the most representative DPP4-i within the Italian setting, compared with the current standard of care (sulfonylureas, SUs), as second-line therapy in add-on to Met, was developed from both societal and Italian National Health Service (INHS) perspectives.

\section{Methods}

A CCA was carried out with the aim to compare SITA and $\mathrm{SU}$, as second-line therapy in add-on to Met, in terms of both costs and related events from both INHS and the societal perspectives.

A dynamic CCA, programmed in Microsoft Excel 2010, was developed in order to capture costs and outcomes in a hypothetical cohort of 100,000 T2DM patients uncontrolled with Met monotherapy, over a 3-year time horizon.

To simulate patient progression and switch to insulin therapy over the time horizon of the analysis, data from the ODYSSEE study were included into the model. ${ }^{11}$ The ODYSSEE study aimed at assessing in a real-world setting the maintenance of treatment in T2DM patients using dual therapy with either Met and SITA or Met and SU. Maintenance rates from ODYSSEE study were applied to the model on a 6-month basis.

The model developed considered resources utilization related to drugs, distribution, glycemia self-monitoring devices, specialist visits, major cardiovascular events (MACEs) and hypoglycemia according to the different treatments. Switching to following treatment line was also included in the model. Both direct and indirect costs (expressed in euro, $€$ ) were considered. As the analysis was performed through a short time horizon, no discount rate was applied as recommended by guidelines of the International Society of Pharmacoeconomics and Outcomes Research (ISPOR). ${ }^{12}$

Furthermore, as many of the included costs were collected through national tariffs, no adjustment was done for a common base year. 
Direct costs included in the model comprised costs borne by the INHS because of specialist visits (eg, diabetologist), hospitalizations due to severe hypoglycemic events, pharmacological therapy, self-monitoring of blood glucose, and switch to following line of therapy. Indirect costs referred to costs falling outside the health care sector and concerned productivity lost (work days/hours lost) due to diabetes complications.

\section{Outcomes}

Hypoglycemic (severe and non-severe) and MACEs were included representing the main drug- and disease-related complications.

Epidemiologic and efficacy data used in the analysis were collected through national and international literature as well as published report of clinical trial and meta-analysis on the basis of the opinion of clinical experts involved in the analysis (FB, SG, and ET). Resource consumption was quantified by using data from literature, when available, or through experts' opinions. Details of the parameters used in the analysis are reported in the next sections.

\section{Efficacy and clinical events}

The analysis considered complications associated with the different treatments in order to provide a realistic overview of the burden related to both therapeutic strategies. In particular, the incidence of severe and nonsevere hypoglycemic events, MACEs, and the maintenance on OADs prior to the shift to insulin therapy were accounted for. As reported in the literature, both SU and DPP4-i showed the same efficacy in controlling blood glucose but different rates of hypoglycemic and major cardiovascular (CV) events. ${ }^{7,8}$

\section{Severe and non-severe hypoglycemic events}

Incidence data about severe and non-severe hypoglycemic events for patients treated with OADs were collected from a clinical trial by Arechavaleta et al. ${ }^{13}$

\section{Incidence of MACE}

MACE incidence rates were collected through a metaanalysis performed by Monami et al. ${ }^{14}$ (aimed at comparing the risk of cardiovascular events and mortality in T2DM patients treated with SU versus DPP4-i). ${ }^{14}$

\section{Switch to insulin rates}

Several observational studies showed different maintenance rates between DPP4-i and SU as second-line treatment in add-on to Met. ${ }^{11,15-18}$ In particular, the ODYSSEY Study showed that dual therapy with Met+SITA can be maintained for longer than Met+SU. ${ }^{11}$

Conversely, a proportion of patients needed a treatment intensification mainly represented by starting an insulinbased regimen. Based on expert opinion we considered the adding of basal insulin in patients not maintaining initial treatment with SITA+Met or SU+Met over time. Specific resources utilization data for insulin regimen were applied into the model including the incidence of non-severe and severe hypoglycemic events. ${ }^{17,18}$

Details of parameters used in the analysis are reported in Table 1.

\section{Economic data and resource utilization}

The following costs were taken into account: drugs, SMBG, specialist visits, main diabetes' complications, and costs related to the switch to insulin therapy.

Table I Parameters used to model clinical events, parameters' value, and source of data

\begin{tabular}{|c|c|c|c|c|}
\hline Parameter type & SITA & SU & Insulin & Source \\
\hline Frequency of monthly glucose automonitoring & $8.3^{\mathrm{a}}$ & $50^{\mathrm{b}}$ & $75^{c}$ & SID - AMD national guidelines ${ }^{6}$ \\
\hline Yearly incidence of non-severe hypoglycemic events & $7 \%$ & $22 \%$ & $8.6 \%$ & Arechavaleta et al $(2011){ }^{13}$ Sreenan et al $(2014)^{17}$ \\
\hline Yearly incidence of severe hypoglycemic events & $0.19 \%$ & $1.16 \%$ & $11.8 \%$ & Arechavaleta et al $(20 \mathrm{II}) ;^{13}$ Leese et al $(2003)^{18}$ \\
\hline Yearly incidence of MACE & $0.97 \%$ & $1.86 \%$ & - & Monami et al $(2013)^{14}$ \\
\hline \multicolumn{5}{|l|}{ Switch to insulin } \\
\hline 6 months & $14 \%$ & $26 \%$ & - & Valensi et al $(2015)^{11}$ \\
\hline 12 months & $24 \%$ & $38 \%$ & - & \\
\hline 18 months & $31 \%$ & $47 \%$ & - & \\
\hline 24 months & $36 \%$ & $54 \%$ & - & \\
\hline 30 months & $41 \%$ & $56 \%$ & - & \\
\hline 36 months & $44 \%$ & $59 \%$ & - & \\
\hline
\end{tabular}

Notes: ${ }^{\text {TTh SID } ~-~ A M D ~ n a t i o n a l ~ g u i d e l i n e s ~ i n d i c a t e d ~} 25$ over 3 months for DPP4-i. bMinimum mean value per month among the three different ranges suggested for SU in the SID - AMD national guidelines: (25-50), (50-75), (75-100). Minimum value in the recommended range suggested for insulin in the SID - AMD national guidelines: (75-100). ' - ' indicates not included in the analysis.

Abbreviations: DPP4-i, dipeptidyl peptidase 4 inhibitors; MACE, major cardiovascular events; SITA, sitagliptin; SU, sulfonylurea; 
Direct costs were valued on the basis of national tariffs or prices listed in official documents, when available, otherwise previously published data have been used.

Indirect costs referred to productivity loss (because of hypoglycemic or cardiovascular events) were valued using the human capital approach thus multiplying working days/ working hours lost due to diabetes-related events by mean daily/hour wages.

\section{Direct costs}

\section{Drug cost and distribution}

Considering the perspective of INHS, net prices including all mandatory discounts and government measures were considered in the analysis. Generic drugs, such as Met and SUs, were valued according to net public price derived from national list - "Lista di trasparenza" - set by the Italian Medicines Agency (AIFA). ${ }^{19}$ An average price among all SUs currently available was considered (Table S1).

For SITA, the net ex-factory price at the time of the analysis was considered. In order to provide a comprehensive cost scenario, also distribution margins were included into the analysis. For Met and SU, distribution margins were included into public price as they are distributed through retail channel. According to SITA prevalent distribution channel (direct distribution of drugs included in the National Hospital-Territory Formulary [PHT]), distribution margins depend on regional agreements. To make this calculation, all regional agreements were collected and weighted for regional population proportion on total.

The average daily dosage in clinical practice of drugs included in the CCA was defined according to expert opinion.

\section{Visits}

Specialist visits were valued through national tariffs. ${ }^{20}$ Frequency of specialists' visits was elicited from experts, and it was assumed to be of two visits per year in both SITA and SU arms and equal to three visits per year for patients switching to insulin-based regimen considering an increasing complexity for these patients' management.

\section{Self-monitoring of blood glucose}

The cost of SMBG per patient was obtained by multiplying single test costs by the recommended average monthly tests for glycemic control, collected through the literature. ${ }^{6}$

Daily cost for SMBG devices including distribution fees was calculated as an average of all costs published by Italian regional health authorities weighted for their population proportion.

\section{Severe and non-severe hypoglycemia}

Direct medical costs associated with hypoglycemic events were obtained from Nicolucci ${ }^{21}$ reporting a direct cost due to severe events ranging between $€ 2,300$ and $€ 3,500$ in primary and secondary diagnosis, respectively. The average mean cost weighted by the frequency of occurrence as primary $(40.5 \%)$ or secondary $(59.5 \%)$ diagnosis was considered in the analysis $(€ 3,014)$.

Based on expert opinion, in the case of non-severe hypoglycemia, it was assumed that only $25 \%$ of all non-severe hypoglycemic events would require a visit by the GP. The tariff for a GP visit was retrieved through Mannocci et al. ${ }^{22}$

\section{MACES}

As MACE is a composite end point, the cost of an event was estimated as weighted average of costs associated with myocardial infarction, stroke, CV death, and revascularization. The incidence of the different events was used as weight, and cost of each single event was collected through the literature and national tariffs (Table S2). ${ }^{22-27}$

\section{Switch to insulin costs}

It was assumed that all patients not maintaining initial treatment with SITA+Met or SU+Met switched to an insulinbased regimen. In order to provide a comprehensive overview of all costs related to insulin switch, the following cost components were included:

- Drug costs, according to net ex-factory daily price of insulin glargine from AIFA and a daily administration of $0.31 \mathrm{UI} / \mathrm{kg}$ (on the basis of expert opinions and data from the Origin trial) for a subject with an average weight of $70 \mathrm{~kg} \cdot{ }^{19,28,29}$

- SMBG device costs and frequencies related to the insulin regimen. ${ }^{6}$

- Incidence of non-severe and severe hypoglycemic events in patients treated with insulin and related costs as reported in the abovementioned section. . $^{17,18,21,22}$

- Diabetologist visits (the frequency of which has been collected through experts' opinion and costs through national tariffs 20$){ }^{20}$

\section{Indirect costs}

In order to calculate the indirect costs, working days/working hours lost due to hypoglycemic events and MACE were collected through the literature and valued multiplying by the number of days/hours of lost productivity by daily/hour wage. ${ }^{30-33}$ 
Values and details of all parameters used to model costs are reported in Table 2 .

\section{Scenario analysis}

In order to provide a more comprehensive overview, a scenario analysis excluding MACE was also performed with the aim to assess the net economic impact related to SITA compared with SU from both perspectives.

\section{One way sensitivity analysis (OWSA)}

An OWSA was carried out in order to assess parameter uncertainty, by varying all the main critical parameters included in the analysis. In particular, the OWSA was performed on the following parameters, by varying the base case value of $\pm 25 \%$ :

- $\quad$ SITA drug cost (range $\pm 25 \%$ of base case value);

- SU drug costs;

- $\mathrm{SMBG}$ of both SITA and SU (range $\pm 25 \%$ of base case value);

- MACE rate (range $\pm 25 \%$ of base case value);

- severe and non-severe hypoglycemic event rate (range $\pm 25 \%$ of base case value);

- direct costs of MACE (range $\pm 25 \%$ of base case value); and

- direct costs of severe hypoglycemic event (range $\pm 25 \%$ of base case value).

OWSA results have been displayed in a tornado diagram, according to the ISPOR guidelines. ${ }^{12}$

\section{Results \\ Base case scenario}

The analysis showed that SITA+Met versus SU+Met was cost saving from both the societal $(-€ 61,217,723)$ and the INHS (-€51,846,442) perspectives over a 3-year time horizon (Tables 3 and 4). In fact, higher drug costs related to SITA+Met $(+€ 83,387,970)$ were offset by other costs for disease management after the 36 months follow-up. That was mainly due to lower use of devices for SMBG, lower

Table 3 Cost-consequence analysis SITA versus SU over 3-year time horizon (societal perspective)

\begin{tabular}{llll}
\hline Cost component & SITA+Met & SU+Met & Delta \\
\hline Drug & $€ 96,600,960$ & $€|3,2| 2,990$ & $€ 83,387,970$ \\
Distribution PHT & $€|6,807,08|$ & $€ 0$ & $€|6,807,08|$ \\
Self-monitoring & $€ \mid 6,518,556$ & $€ 80,368,536$ & $-€ 63,849,980$ \\
Visits & $€ 8,94 \mid, 648$ & $€ 7,221,703$ & $€ I, 7 \mid 9,945$ \\
Hypos & $€ I, 296,239$ & $€ 6,255,7 \mid 6$ & $-€ 4,959,477$ \\
MACE & $€ 0$ & $€ 23,501,390$ & $-€ 23,50 \mid, 390$ \\
Switch to insulin & $€|23,4| 7,88$ & $€ \mid 84,868,478$ & $-€ 6 \mid, 450,592$ \\
Indirect costs & $€ 2,154,480$ & $€|I, 525,76|$ & $-€ 9,37|, 28|$ \\
Total costs & $€ 265,736,850$ & $€ 326,954,574$ & $-€ 6|, 2| 7,723$ \\
\hline
\end{tabular}

Abbreviations: hypos, hypoglycemic events; MACE, major cardiovascular events; SITA, sitagliptin; SU, sulfonylurea; PHT, drugs included in the National HospitalTerritory Formulary.

Table 4 Cost-consequence analysis SITA versus SU over 3-year time horizon (INHS perspective)

\begin{tabular}{llll}
\hline Cost component & SITA+Met & SU+Met & Delta \\
\hline Drug & $€ 96,600,960$ & $€|3,2| 2,990$ & $€ 83,387,970$ \\
Distribution PHT & $€|6,807,08|$ & $€ 0$ & $€|6,807,08|$ \\
Self-monitoring & $€|6,5| 8,556$ & $€ 80,368,536$ & $-€ 63,849,980$ \\
Visits & $€ 8,94 \mid, 648$ & $€ 7,22 \mid, 703$ & $€ I, 7 \mid 9,945$ \\
Hypos & $€ I, 296,239$ & $€ 6,255,7 \mid 6$ & $-€ 4,959,477$ \\
MACE & $€ 0$ & $€ 23,50 \mid, 390$ & $-€ 23,50 \mid, 390$ \\
Switch to insulin & $€|23,4| 7,886$ & $€ \mid 84,868,478$ & $-€ 6 \mid, 450,592$ \\
Indirect costs & $€ 0$ & $€ 0$ & $€ 0$ \\
Total costs & $€ 263,582,370$ & $€ 3|5,428,8| 3$ & $-€ 5 I, 846,442$ \\
\hline
\end{tabular}

Abbreviations: hypos, hypoglycemic events; INHS, Italian National Health Service; MACE, major cardiovascular events; Met, metformin; SITA, sitagliptin; SU, sulfonylurea; PHT, drugs included in the National Hospital-Territory Formulary.

Table 2 Unit costs (Euros) associated with resource item and source of data

\begin{tabular}{|c|c|c|}
\hline Resource Item & Unit cost & Details and source \\
\hline \multicolumn{3}{|l|}{ Direct costs } \\
\hline Met & $€ 0.06 /$ die & Italian Medicines Agency ${ }^{19}$ \\
\hline SITA+Met & $€ I .24 / \mathrm{die}$ & Ex-factory daily net price \\
\hline SU+Met & $€ 0.21 / \mathrm{die}$ & Italian Medicines Agency, ${ }^{19}$ refer Table SI for details \\
\hline Insulin & $€ 0.03 / I U$ & Ex-factory daily net price \\
\hline Strips & $€ 0.506$ & Mean value over regional data \\
\hline Needles & $€ 0.116$ & Mean value over regional data \\
\hline Outpatient visit & $€ 20.66$ & Italian Ministry of Health $2013^{20}$ \\
\hline Severe hypoglycemia & $€ 3,0 \mid 4$ & Nicolucci $(2014)^{21}$ \\
\hline GP visit for non-severe hypoglycemia & $€ I 5.24$ & Mannocci et al (2009) $)^{22}$ \\
\hline MACE & $€|5,04|$ & Literature + calculation as detailed in Table S2 \\
\hline \multicolumn{3}{|l|}{ Indirect costs } \\
\hline Cost/day & $€ 100$ & $€ 25,200$ (GDP)/25I (working days per year), European statistics ${ }^{32}$ \\
\hline Cost/hour & $€ 13$ & Cost per day $/ 7.72^{32,33}$ \\
\hline Severe hypoglycemia & $€ 663$ & Calculation \\
\hline Non-severe hypoglycemia & $€ 124$ & Calculation \\
\hline
\end{tabular}

Abbreviations: GDP, gross domestic product; GP, general practitioner; MACE, major cardiovascular events; Met, metformin; SITA, sitagliptin; SU, sulfonylurea. 
incidence of hypoglycemia and CV events, indirect costs, and insulin delay (durability).

The analysis also showed that SITA adoption (as add-on to Met) would avoid over a 100,000 subjects cohort and a 3-year time horizon:

- 26,882 non-severe hypoglycemic events;

- 6,528 severe hypoglycemic events; and

- 1,562 major CV events (Figure 1).

\section{Scenario analysis (without MACE)}

Even in the scenario analysis excluding MACE, results showed that SITA+Met versus SU+Met was cost saving from both societal and INHS perspectives over a 3-year time horizon (Tables 5 and 6).

\section{OWSA}

The OWSA, performed to assess the robustness of base case results, showed that the results of the base case analysis were robust with respect to all critical parameters ranging from a minimum saving of $€ 37$ million (in the unlikely scenario of $25 \%$ increasing of SITA acquisition cost) to a maximum of $€ 87$ million (in the scenario assuming a $25 \%$ reduction of SITA acquisition cost). Except from SITA acquisition cost, as reported in the tornado graph, the most influential parameters were SU acquisition costs and SU SMBG frequencies (Figure 2).

\section{Discussion}

Results from the present analysis suggest that, over a 3-year time horizon, SITA+Met versus SU+Met, for the treatment of diabetic subjects uncontrolled with Met monotherapy, could be a safe, sustainable, and cost-saving alternative for the management of diabetes from both clinical and economic point of view.

Moreover, the economic impact was favorable both when adopting the INHS and the societal perspective because of the better impact of SITA in terms of lower incidence of complications.

Table 5 Scenario analysis: cost-consequence analysis SITA versus SU over 3-year time horizon (societal perspective) without MACE

\begin{tabular}{|c|c|c|c|}
\hline Cost component & SITA+Met & SU+Met & Delta \\
\hline Drug & $€ 96,600,960$ & $€|3,2| 2,990$ & $€ 83,387,970$ \\
\hline Distribution PHT & $€|6,807,08|$ & $€ 0$ & $€|6,807,08|$ \\
\hline Self-monitoring & $€ 16,518,556$ & $€ 80,368,536$ & $-€ 63,849,980$ \\
\hline Visits & $€ 8,941,648$ & $€ 7,221,703$ & $€ ।, 7 \mid 9,945$ \\
\hline Hypos & $€ 1,296,239$ & $€ 6,255,716$ & $-€ 4,959,477$ \\
\hline MACE & $€ 0$ & $€ 0$ & $€ 0$ \\
\hline Switch to insulin & $€|23,4| 7,886$ & $€ \mid 84,868,478$ & $-€ 6 I, 450,592$ \\
\hline Indirect costs & $€ 2,154,480$ & $€|I, 525,76|$ & $-€ 9,37|, 28|$ \\
\hline Total costs & $€ 265,736,850$ & $€ 303,453,184$ & $-€ 37,716,334$ \\
\hline
\end{tabular}

Abbreviations: hypos, hypoglycemic events; MACE, major cardiovascular events; Met, metformin; SITA, sitagliptin; SU, sulfonylurea; PHT, drugs included in the National Hospital-Territory Formulary.

Table 6 Scenario analysis: cost-consequence analysis SITA versus SU over 3-year time horizon (INHS perspective) without MACE

\begin{tabular}{llll}
\hline Cost voices & SITA+Met & SU+Met & Delta \\
\hline Drug & $€ 96,600,960$ & $€|3,2| 2,990$ & $€ 83,387,970$ \\
Distribution PHT & $€ \mid 6,807,08 \mathrm{I}$ & $€ 0$ & $€ \mid 6,807,08 \mathrm{I}$ \\
Self-monitoring & $€|6,5| 8,556$ & $€ 80,368,536$ & $-€ 63,849,980$ \\
Visits & $€ 8,94 I, 648$ & $€ 7,221,703$ & $€ I, 7 \mid 9,945$ \\
Hypos & $€ I, 296,239$ & $€ 6,255,7 \mid 6$ & $-€ 4,959,477$ \\
Switch to insulin & $€|23,4| 7,886$ & $€ \mid 84,868,478$ & $-€ 6 \mid, 450,592$ \\
Total costs & $€ 263,582,370$ & $€ 29 \mid, 927,423$ & $-€ 28,345,053$ \\
\hline
\end{tabular}

Abbreviations: hypos, hypoglycemic events; INHS, Italian National Health Service; MACE, major cardiovascular events; Met, metformin; SITA, sitagliptin; SU, sulfonylurea; PHT, drugs included in the National Hospital-Territory Formulary.

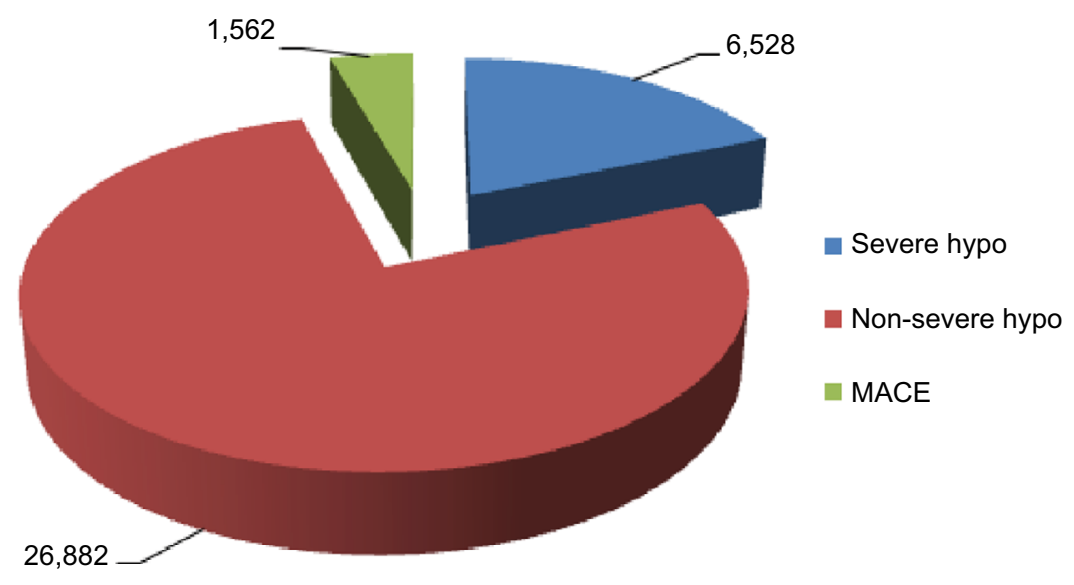

Figure I Avoided events SITA+Met versus SU+Met.

Abbreviations: hypo, hypoglycemic event; MACE, major cardiovascular events; Met, metformin; SITA, sitagliptin; SU, sulfonylurea. 


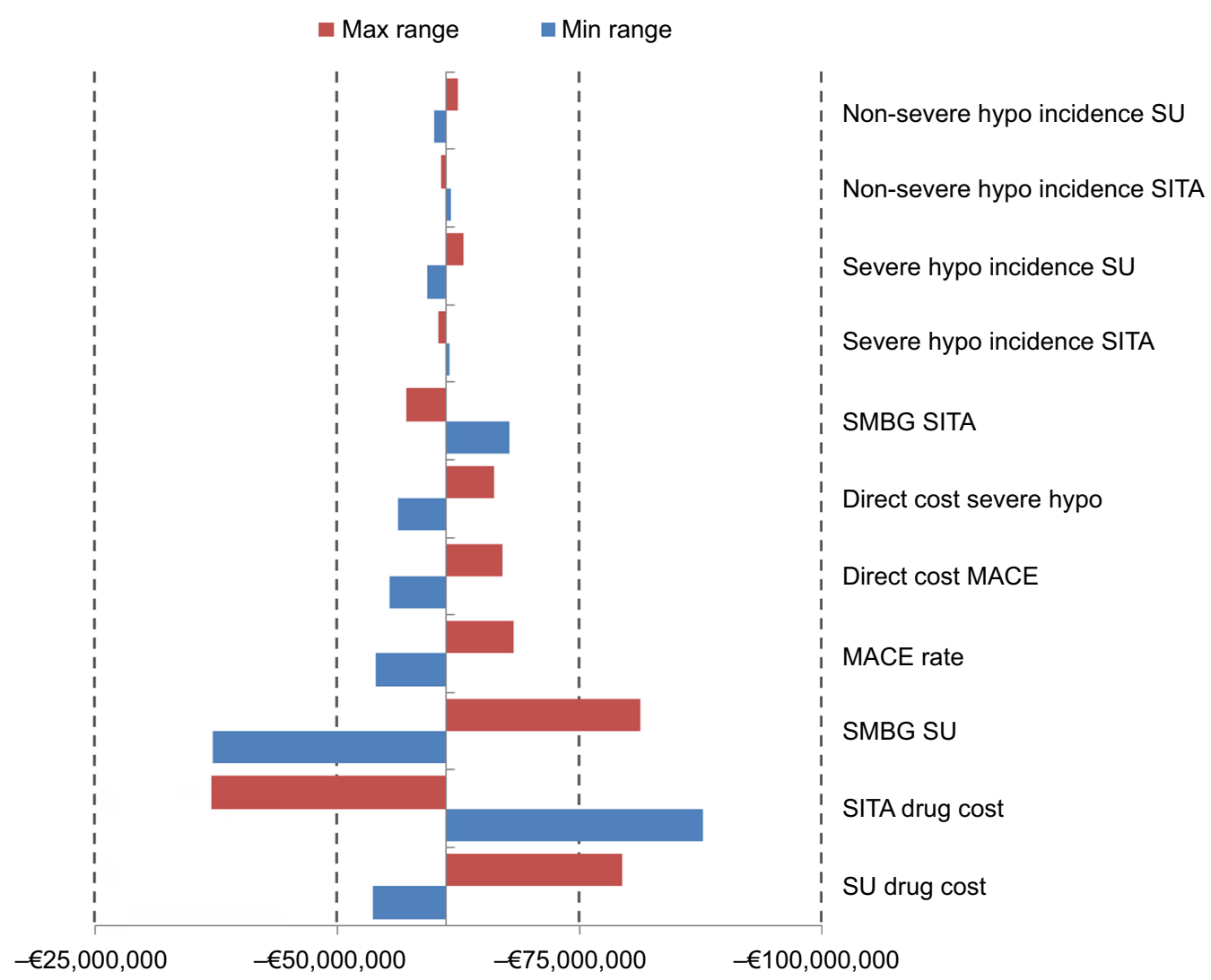

Figure 2 One-way sensitivity analysis: tornado graph.

Abbreviations: hypo, hypoglycemic event; MACE, major cardiovascular events; Met, Metformin; SITA, sitagliptin; SMBG, self-monitoring of blood glucose; SU, sulfonylurea.

Despite the significantly higher acquisition costs, SITA overall cost resulted lower than SU due to the lower use of devices for SMBG, the lower incidence of hypoglycemia and $\mathrm{CV}$ events, and the higher rate of maintenance on therapy thus resulting in a lower switch to insulin-based regimen.

The present analysis highlights the importance, within the health care sector, to go beyond a silos approach by adopting a holistic view in the light of value-based health care. This approach could allow considering all the variables generating the whole value of a new technology adoption within a specific environment.

A potential risk of not implementing a value-based approach is related to suboptimal health care decision making where reaching financial target on selected budget could generate an overall cost increasing and/or providing less favorable outcomes for the patients.

While innovations in the health care sector have grown exponentially in the last few decades, their adoption is sometimes limited because of the extra expenditure for their acquisition. In order to set priorities and to adequately balance costs and consequences, comprehensive information on those outcomes are crucial.
This is particularly critical for chronic care diseases such as diabetes which is associated with a significant epidemiologic and economic burden and is expected to increase significantly in the next few years due to aging and lifestyle changing.

Within this framework, adopting a holistic approach to antidiabetic technology assessment represents a critical factor for health services sustainability in the long term allowing to optimize resource allocation and to maximize patient outcomes, avoiding direct and indirect costs related to diabetes complications.

The first DPP4-i (SITA) has been introduced in the Italian market, with indication for the treatment of T2DM patients, approximately 10 years ago. The amount of data and evidence which have been generated over this period of time allowed us to perform a CCA considering evidence gathered both at national and international level to guide informed decision making.

In Italy, the use of innovative OADs, such as DPP4i, is still limited diabetic patients. ${ }^{34}$ According to the data from national prescription database (OsMed), 64.4\% of patients potentially eligible for treatment with DPP4-i are not currently treated with these drugs, mainly due to their prescription limitation to specialists. According to recent Italian 
diabetes management reports, it is assumed that 3.6 million people are affected by diabetes and that approximately 3 million are treated with antidiabetic drugs. ${ }^{34}$

Among these patients, only 1 million are in the charge of specialist while 2 million are currently in the charge of GPs. ${ }^{35}$

Given the number of diabetic patients in Italy, being about $3,266,681$ in 2012 and considering that $64.4 \%$ of them could be eligible for treatment with DPP4-i, because satisfying criteria and limit established for DPP4-i reimbursement, it follows that, on the basis of the present analysis, the clinical and economic burden may be reduced, at least in the midterm, by the extension of the treatment with DPP4-i. ${ }^{34,36}$

Moreover, recent studies confirmed the safety of SITA even in diabetic patients with cardiovascular disease. ${ }^{37,38}$ Another study also suggested a possible effect of SITA in reducing both cholesterol level and blood pressure that, combined with an effective $\mathrm{HbA}_{1 \mathrm{c}}$ control, involves a reduction of about $7.5 \%$ in the yearly incidence of myocardial infarction as compared to competitors. ${ }^{39}$

Furthermore, recent real-life studies showed that the use of SITA or other DPP4-i in combination with Met, compared to $\mathrm{SU}$ or insulin, reduces the onset of hypoglycemia and mortality. ${ }^{40-42}$

In particular, an observational study of $\sim 6$ years, conducted on 52,760 patients, compared cardiovascular risk, mortality for all causes, and episodes of severe hypoglycemia in patients with T2DM treated with Met+SU versus Met+DPP4-i (80.3\% treated with SITA). Results showed an increased risk in patients treated with Met+SU compared with Met+DPP4-i for all the end points. Of note, the increased risk in Met+SU patients was significant by the first 6 months of treatment and continued to increase over the duration of the observation period. ${ }^{40}$

A retrospective analysis conducted on the OsMed database and including 32 Italian local health authorities (accounting for 30\% of the country's population) assessed the association between heart failure (HF) risk with DPP4-i and SU in 127,555 T2DM patients. During the follow-up period, lasting on average 2.6 years, DPP4-i use was associated with a reduced risk of HF compared with SU. ${ }^{42}$

Even insulin switch delay with SITA was shown in a reallife study analyzing the progression to starting insulin therapy over a 7-year period in a sample of 7,728 patients. Results showed that patients treated with SITA had a significant lower risk of progression toward insulin therapy as compared with SU $(26.6 \%$ versus $34.1 \%){ }^{43}$

The economic evaluation performed has some limitations that could affect the results of the analysis. A major limit relies on the fact that, as the analysis is not an empirical evaluation, it does not take into account possible differences in the demographic and clinical characteristics of the patients. Moreover, given the relatively shortness of the time horizon assumed, the analysis does not consider the impact of insulin therapy on clinical events and cardiovascular complications with possible related costs. Finally, given the lack of data, compliance was not considered in the study and it was assumed to be the same in both treatments (equal to $100 \%$ in both groups).

Despite the inherent limitations discussed, to our knowledge, the current study represents the first study performing a comprehensive economic evaluation of SITA and SU by including also indirect costs in Italy. Moreover, although CCA is sometimes considered less rigorous than other economic evaluation, it is at the same time more versatile and practical being able to offer clear and simple information thus representing a valid framework for appraising appropriate treatment for diabetic patients in the Italian context.

\section{Acknowledgments}

The analysis was supported by Merck Sharp \& Dohme which sponsored the development of the cost-consequence model and data validation.

\section{Disclosure}

$\mathrm{FB}$, in the last 3 years, has received consultancy and/or speaking fees from: Eli Lilly and MSD Italy. SG, in the last 3 years, has received consultancy and/or speaking fees and research grants from: Abbott Diabetes Care, AstraZeneca, Boehringer Ingelheim, Bristol-Myers Squibb, Bruno Farmaceutici, Eli Lilly, Janssen, Johnson \& Johnson, Menarini, MSD Italy, Novo Nordisk, Novartis, Sano and Takeda. ET, in the last 3 years, has received consultancy and/or speaking fees and research grants from: AstraZeneca, Boehringer Ingelheim, Bristol-Myers Squibb, Eli Lilly, GSK, Janssen, Johnson \& Johnson, MSD Italy, Novo Nordisk, Sano and Takeda. The authors report no other conflicts of interest in this work.

\section{References}

1. IDF. International Diabetes Federation: IDF Diabetes Atlas. 7th ed. Brussels: International Diabetes Federation; 2013. Available from: www.diabetesaltlas.org. Accessed September 20, 2016.

2. Epicentro [webpage on the Internet]. La patologia diabetica: dati di prevalenza a livello Nazionale. 2015. [Diabetes: prevalence data at the Italian national level]. Available from: http://www.epicentro.iss.it/igea/ diabete/prevalenza.asp. Accessed September 20, 2016.

3. Pagano E, De Rosa M, Rossi E, et al. The relative burden of diabetes complications on healthcare costs: the population-based CINECA-SID ARNO diabetes observatory. Nutr Metab Cardiovasc Dis. 2016;26(10):944-950.

4. Ravasio R. Analisi di costo-efficacia di exenatide versus insulina glargine nel trattamento dei pazienti diabetici di tipo 2 in fallimento secondario al doppio ipoglicemizzante orale. [Cost-effectiveness analysis of exenatide versus glargine insulin in the treatment of type II diabetic patients failing double hypoglycemic oral therapy]. G Ital Health Technol Assess. 2008;1(1):21-30. Italian. 
5. Marcellusi A, Viti R, Mecozzi A, Menninni FS. The direct and indirect cost of diabetes in Italy: a prevalence probabilistic approach. Eur $J$ Health Econ. 2014;17(2):139-147.

6. AMD Associazione dei Medici Diabetologi - [SID] Società Italiana di Diabetologia. Standard italiani per la cura del diabete mellito. 2016. [AMD Italian Association of Clinical Diabetologists - SID Italian Diabetes Society. Italian standard for diabetes mellitus 2016]. Available from: http://www.standarditaliani.it/skin/www.standarditaliani.it/pdf/ STANDARD_2016_June20.pdf. Accessed February 8, 2017. Italian.

7. Krobot K, Ferrante SA, Davies MJ, et al. Lower risk of hypoglicemia with sitagliptin compared to glipizide when either is added to metformin therapy: a pre-specified analysis adjusting for the most recently measured $\mathrm{HbA}_{1 \mathrm{c}}$ value. Curr Med Res Opin. 2012;28(8): 1281-1287.

8. Ferrannini E, Fonseca V, Zinman B, et al. Fifty-two-week efficacy and safety of vildagliptin vs. glimepiride in patients with type 2 diabetes mellitus inadequately controlled on metformin monotherapy. Diabetes Obes Metab. 2009;11(2):157-166.

9. Karagiannis T, Paschos P, Paletas K, Matthews D, Tsapas A. Dipeptidyl peptidase-4 inhibitors for treatment of type 2 diabetes mellitus in the clinical setting: systematic review and meta-analysis. BMJ. 2012;344: e1369.

10. [SID] Società Italiana di Diabetologia. Il diabete in Italia. [SID Italian Diabetes Society. Diabetes in Italy]. Bologna, Italy: Bononia University Press; 2016. Italian.

11. Valensi P, de Pouvourville G, Benard N, et al. Treatment maintenance duration of dual therapy with metformin and sitagliptin in type 2 diabetes: The ODYSSEE observational study. Diabetes Metab. 2015;41(3):231-238.

12. Husereau D, Drummond M, Petrou S, et al; ISPOR Health Economic and Evaluation Publication Guidelines- CHEERS Good Reporting Practices Task Force. Consolidated health economic evaluation reporting standards (CHEERS)-explanation and evaluation: a report of the ISPOR health economic evaluation publication guidelines good reporting practices task force. Value Health. 2013;16(2):231-250.

13. Arechavaleta R, Seck T, Chen Y, et al. Efficacy and safety of treatment with sitagliptin or glimepiride in patients with type 2 diabetes inadequately controlled on metformin monotherapy: a randomized, double-blind, non-inferiority trial. Diabetes Obes Metab. 2011;13(2): 160-168.

14. Monami M, Genovese S, Mannucci E. Cardiovascular safety of sulfonylureas: a meta-analysis of randomized clinical trials. Diabetes Obes Metab. 2013;15(10):938-953.

15. Pirolo R, Bettiol A, Bolcato J, et al. Cost-of-illness study of diabetes mellitus: focus on patients with type 2 diabetes. GRHTA. 2016;3(1): $32-41$.

16. Degli Esposti L, Saragoni S, Buda S, Degli Esposti E. Clinical outcomes and health care costs combining metformin with sitagliptin or sulphonylureas or thiazolidinediones in uncontrolled type 2 diabetes patients. Clinicoecon Outcomes Res. 2014;6:463-472.

17. Sreenan S, Andersen M, Thrsted BL, Wolden ML, Evans M. Increased risk of severe hypoglycemic events with increasing frequency of nonsevere hypoglycemic events in patients with type 1 and type 2 diabetes. Diabetes Ther. 2014;5(2):447-458.

18. Leese GP, Wang J, Broomhall J, et al; DARTS/MEMO Collaboration. Frequency of severe hypoglycemia requiring emergency treatment in type 1 and type 2 diabetes: a population-based study of health service resource use. Diabetes Care. 2003;24(4):11760-11780.

19. AIFA [webpage on the Internet]. Italian Medicines Agency. 2016. Available from: http://www.agenziafarmaco.gov.it/content/liste-ditrasparenza-e-rimborsabilità. Accessed September 20, 2016.

20. Italian Ministry of Health [webpage on the Internet]. Italian National Tariffs. 2013. Available from: http://www.gazzettaufficiale.it/eli/ id/2013/01/28/13A00528/sg. Accessed September 20, 2016.

21. Nicolucci A. L'ipoglicemia: le varie dimensioni del problema in Italia. GAMD. 2014;17(suppl 3):5-9.
22. Mannocci A, Marocco A, Gualano MR, Capri S, La Torre G, Ricciardi W. Consumo di risorse e costi associati al trattamento delle patologie sostenute da Streptococcus pneumoniae (Spn) ed Haemophilus influenzae non tipizzabile (NTHi). [Resource use and costs associated with the treatment of Streptococcus pneumoniae (Spn) and Haemophilus influenzae non-typable (NTHi)]. Ital J Public Health. 2009;6(suppl 5):S20-S33. Italian.

23. Monesi G. Dalla epidemiologia clinica alle strategie assistenziali. Uso e lettura dei dati amministrativi. Presentazione a CONVEGNO "La malattia diabetica in Veneto dal 1997 al 2002. Dalla Epidemiologia Clinica alle Stategie Assistenziali. [From clinical epidemiology to strategy for care. Use of administrative data. Congress presentation "Diabetic disease in Veneto 1997-2002. From Clinical Epidemiology to Strategies for Assistence]. Rovigo: Cittadella SocioSanitaria; 2005. Italian.

24. Berto P, Inzatari D, Scrutinio D, et al. Clopidogrel idrogenosolfato versus aspirina nella riduzione degli eventi aterotrombotici nelle popolazioni a elevato rischio cardiovascolare: un'analisi italiana di costo-efficacia basata sul trial CAPRIE. [Clopidogrel hydrogen sulphate versus aspirin in the reduction of atherothrombotic events in high cardiovascular risk populations: an Italian cost-effectiveness analysis based on the CAPRIE trial]. Pharmacoeconomics Ital Res Articles. 2010;12(1):33-50. Italian.

25. Fattore G, Torbica A, Susi A, et al. The social and economic burden of stroke survivors in Italy: a prospective, incidence-based, multi-centre cost of illness study. BMC Neurol. 2012;12:137.

26. Lucioni C, Garancini MP, Massi-Benedetti M, et al. Il costo sociale del diabete di tipo 2 in Italia: lo studio CODE-2. [Cost of illness of type II diabetes in Italy: the CODE-2 study]. Pharmacoeconomics Ital Res Articles. 2000;2(1):1-21. Italian.

27. Rapporto annuale sull'attività di ricovero ospedaliero SDO. [Annual report on hospital admissions in Italy]. Dati SDO 2012. Rome: Italian Ministry of Health; 2013. Italian.

28. Origin Trial investigators, Gerstein HC, Bosch J, et al. Basal insulin and cardiovascular and other outcomes in dysglycemia. $N$ Engl J Med. 2012;367(4):319-328.

29. Indagine Multiscopo sulle famiglie: aspetti della vita quotidiana [webpage on the Internet]. [Multiscope survey on families: aspects of everyday life]. Elaborazione File Microdati Anno. Italian Institute of Statistics (ISTAT); 2013. Available from: https://www.istat.it/it/archivio/ microdati+ad+uso+pubblico+storici. Accessed July 13, 2016. Italian.

30. Jonsson L, Bolinder B, Lundkvist J. Cost of hypoglycemia in patients with type 2 diabetes in Sweden. Value Health. 2006;9(3):193-198.

31. Brod M, Christensen T, Thomsen TL, Bushnell DM. The impact of non-severe hypoglycemic events on work productivity and diabetes management. Value Health. 2011;14(5):665-671.

32. Giorni-Lavorativi [database on the Internet]. Working Days and Public Holidays by Contry. 2017. Available from: http://www.giorni-lavorativi. com/EN/giorni-lavorativi_festivi_2014.htm._Accessed February 8, 2017.

33. EUROSTAT European Statistics [database on the Internet]. Gross Domestic Product at Market Prices. 2013. Available from: http://epp. eurostat.ec.europa.eu/tgm/table.do?tab=table\&init=1\&plugin=1\&lang uage $=e n \& p \operatorname{code}=$ tec00001. Accessed February 8, 2017.

34. L'uso dei farmaci in Italia- Rapporto OsMed 2016. [The medicines utilization monitoring centre. national report on medicines use in Italy 2016]. Rome: Italian Medicine Agency, AIFA; 2017. Italian.

35. Thales Group. Market research on Thales database. 2nd Quarter 2016.

36. EPICENTRO. La patologia diabetica: dati di prevalenza a livello nazionale. 2017. [Diabetes: prevalence dataA at italian national level]. Available from: http://www.epicentro.iss.it/igea/diabete/prevalenza.asp. Accessed February 8, 2017. Italian.

37. Shin S, Kim H. The effect of sitagliptin on cardiovascular risk profile in Korean patients with type 2 diabetes mellitus: a retrospective cohort study. Ther Clin Risk Manag. 2016;12:435-444.

38. Green JB, Bethel MA, Armstrong PW, et al; TECOS Study Group. Effect of sitagliptin on cardiovascular outcomes in type 2 diabetes. $N$ Engl $J$ Med. 2015;373(3):232-242. 
39. Monami M, Ahrén B, Dicembrini I, Mannucci E. Dipeptidyl peptidase-4 inhibitors and cardiovascular risk: a meta-analysis of randomized clinical trials. Diabetes Obes Metab. 2013;15(2):112-120.

40. Eriksson JS, Bodegard J, Nathanson D, et al. Sulphonylurea compared to DPP4 inhibitors in combination with metformin carries increased risk of severe hypoglycemia, cardiovascular events, and all-cause mortality. Diabetes Res Clin Pract. 2016;117:39-47.

41. Nyström T, Bodegard J, Nathanson D, Thuresson M, Norhammar A, Eriksson JW. Second line initiation of insulin compared with DPP-4 inhibitors after metformin monotherapy is associated with increased risk of all-cause mortality, cardiovascular events, and severe hypoglycemia. Diabetes Res Clin Pract. 2017;123:199-208.
42. Fadini GP, Avogaro A, Degli Esposti L, et al; OsMed Health-DB Network. Risk of hospitalization for heart failure in patients with type 2 diabetes newly treated with DPP-4 inhibitors or other oral glucoselowering medications: a retrospective registry study on 127,555 patients from the Nationwide OsMed Health-DB Database. Eur Heart J. 2015;36(36):2454-2462.

43. Inzucchi SE, Tunceli K, Qiu Y, et al. Progression to insulin therapy among patients with type 2 diabetes treated with sitagliptin or sulphonylurea plus metformin dual therapy. Diabetes Obes Metab. 2015;17(10):956-964. 


\section{Supplementary materials}

Table SI Details of data used to obtained average costs of drug costs for SU+Met

\begin{tabular}{|c|c|c|c|c|c|c|}
\hline Drug & Dosage & Cpr per pack & Public price & $\begin{array}{l}\text { Ex-factory price } \\
\text { (per cpr) }^{\mathrm{a}}\end{array}$ & Daily cost & $\begin{array}{l}\text { Daily cost } \\
\text { SU+Met }\end{array}$ \\
\hline Gliclazide & Gliclazide 80 mg & 40 & $€ 3.34$ & $€ 0.0445$ & $€ 0.08$ & $€ 0.13$ \\
\hline Gliclazide & Gliclazide $160 \mathrm{mg}$ & & & & $€ 0.15$ & $€ 0.21$ \\
\hline Gliclazide & Gliclazide 240 mg & & & & $€ 0.23$ & $€ 0.28$ \\
\hline Gliclazide rp & Gliclazide 30 mg & 60 & $€ 6.80$ & $€ 0.0604$ & $€ 0.10$ & $€ 0.16$ \\
\hline Gliclazide rp & Gliclazide 60 mg & & & & $€ 0.21$ & $€ 0.26$ \\
\hline Gliclazide rp & Gliclazide $120 \mathrm{mg}$ & & & & $€ 0.4 \mathrm{I}$ & $€ 0.47$ \\
\hline Glimepiride & Glimepiride I mg & & & & $€ 0.03$ & $€ 0.09$ \\
\hline Glimepiride & Glimepiride 2 mg & 30 & $€ 2.12$ & $€ 0.0377$ & $€ 0.06$ & $€ 0.12$ \\
\hline Glimepiride & Glimepiride $3 \mathrm{mg}$ & 30 & $€ 3.56$ & $€ 0.0633$ & $€ 0.11$ & $€ 0.16$ \\
\hline Glimepiride & Glimepiride $4 \mathrm{mg}$ & 30 & $€ 3.56$ & $€ 0.0633$ & $€ 0.11$ & $€ 0.16$ \\
\hline Glimepiride & Glimepiride $5 \mathrm{mg}$ & & & & $€ 0.17$ & $€ 0.23$ \\
\hline Glimepiride & Glimepiride 6 mg & & & & $€ 0.22$ & $€ 0.27$ \\
\hline Glibenclamide & Glibenclamide 5 mg & 30 & $€ 2.94$ & $€ 0.0523$ & $€ 0.09$ & $€ 0.14$ \\
\hline Glibenclamide & Glibenclamide 10 mg & & & & $€ 0.18$ & $€ 0.23$ \\
\hline Average SU+Met price & & & & & & $€ 0.21$ \\
\hline
\end{tabular}

Notes: aPrices from the Italian Medicines Agency.' 'Including metformin daily cost of $€ 0.06$.

Abbreviations: cpr, compress; Met, Metformin; SITA, sitagliptin; SU, sulfonylurea.

Table S2 Details of data used to value direct costs of MACE

\begin{tabular}{|c|c|c|c|c|}
\hline MACE & Costs (€) & Details and reference for costs & Weights & Reference \\
\hline Revascularization & $€ 27,519$ & $\begin{array}{l}\text { Bypass coronarico con PTCA [coronary bypass with PTCA], DRG 106: } \\
\text { Italian Ministry of Health } 2013^{2}\end{array}$ & $30 \%$ & Monesi $(2005)^{3}$ \\
\hline MI & $€ 9,704$ & $\begin{array}{l}€ 4,0 \mid 8 \text { (acute phase, DRG I2I-I22)+€5,686 (I-year costs), DRG I06: } \\
\text { Italian Ministry of Health }(20 \mid 3) ;{ }^{2} \text { Berto et al }(20 \mid 0) .{ }^{4}\end{array}$ & $31 \%$ & Monesi $(2005)^{3}$ \\
\hline Stroke & $€ 10,063$ & $\begin{array}{l}€ 3,98 \text { I (acute phase, DRG I4) }+€ 4, I 32 \text { (first } 3 \text {-months costs) }+€ 680 \\
\text { (subsequent } 3 \text {-months costs): Italian Ministry of Health }(2013) \text {; }^{2} \text { Fattore } \\
\text { et al }(2012) .^{5}\end{array}$ & $35 \%$ & Monesi $(2005)^{3}$ \\
\hline $\mathrm{CV}$ death & $€ 4,348$ & Lucioni et al $(2010)^{6}$ & $4 \%$ & $\begin{array}{l}\text { Italian Hospital discharge } \\
\text { data }(2012)^{7}\end{array}$ \\
\hline \multicolumn{4}{|c|}{ Average costs for MACE } & $€|5,04|$ \\
\hline
\end{tabular}

Abbreviations: CV, cardiovascular; DRG, diagnosis-related group; MACE, major cardiovascular events; MI, myocardial infarction; PTCA, percutaneous transluminal coronary angioplasty.

\section{References}

1. Degli Esposti L, Saragoni S, Buda S, Degli Esposti E. Clinical outcomes and health care costs combining metformin with sitagliptin or sulphonylureas or thiazolidinediones in uncontrolled type 2 diabetes patients. Clinicoecon Outcomes Res. 2014;6:463-472.

2. Italian Ministry of Health [webpage on the Internet]. Italian National Tariffs. 2013. Available from: http://www.gazzettaufficiale.it/eli/ id/2013/01/28/13A00528/sg. Accessed September 20, 2016.

3. Monesi G. Dalla epidemiologia clinica alle strategie assistenziali. Uso e lettura dei dati amministrativi. Presentazione a CONVEGNO "La malattia diabetica in Veneto dal 1997 al 2002. Dalla Epidemiologia Clinica alle Stategie Assistenziali. [From clinical epidemiology to strategy for care. Use of administrative data. Congress presentation "Diabetic disease in Veneto 1997-2002. From Clinical Epidemiology to Strategies for Assistence]. Rovigo: Cittadella SocioSanitaria; 2005. Italian.
4. Berto P, Inzatari D, Scrutinio D, et al. Clopidogrel idrogenosolfato versus aspirina nella riduzione degli eventi aterotrombotici nelle popolazioni a elevato rischio cardiovascolare: un'analisi italiana di costo-efficacia basata sul trial CAPRIE. [Clopidogrel hydrogen sulphate versus aspirin in the reduction of atherothrombotic events in high cardiovascular risk populations: an Italian cost-effectiveness analysis based on the CAPRIE trial]. Pharmacoeconomics Ital Res Articles. 2010;12(1):33-50. Italian.

5. Fattore G, Torbica A, Susi A, et al. The social and economic burden of stroke survivors in Italy: a prospective, incidence-based, multi-centre cost of illness study. BMC Neurol. 2012;12:137.

6. Lucioni C, Garancini MP, Massi-Benedetti M, et al. Il costo sociale del diabete di tipo 2 in Italia: lo studio CODE-2. [Cost of illness of type II diabetes in Italy: the CODE-2 study]. Pharmacoeconomics Ital Res Articles. 2000;2(1):1-21. Italian.

7. Rapporto annuale sull'attività di ricovero ospedaliero SDO. [Annual report on hospital admissions in Italy]. Dati SDO 2012. Rome: Italian Ministry of Health; 2013. 


\section{Publish your work in this journal}

ClinicoEconomics and Outcomes Research is an international, peerreviewed open-access journal focusing on health technology assessment, pharmacoeconomics and outcomes research in the areas of diagnosis, medical devices, and clinical, surgical and pharmacological intervention. The economic impact of health policy and health systems organization also constitute important areas of coverage. The manuscript management system is completely online and includes a very quick and fair peer-review system, which is all easy to use. Visit http://www.dovepress.com/testimonials.php to read real quotes from published authors.

Submit your manuscript here: https://www.dovepress.com/clinicoeconomics-and-outcomes-research-journal 